\title{
Arx Is a Direct Target of Dlx2 and Thereby Contributes to the Tangential Migration of GABAergic Interneurons
}

\author{
Gaia Colasante, ${ }^{1,2 *}$ Patrick Collombat, ${ }^{4 *}$ Valentina Raimondi, ${ }^{1,2}$ Dario Bonanomi, ${ }^{1}$ Carmelo Ferrai, ${ }^{1}$ Mario Maira, ${ }^{5}$ \\ Kazuaki Yoshikawa, ${ }^{6}$ Ahmed Mansouri, ${ }^{4}$ Flavia Valtorta, ${ }^{1,3}$ John L. R. Rubenstein, ${ }^{5}$ and Vania Broccoli ${ }^{1,2}$ \\ ${ }^{1}$ Department of Biological and Technological Research, San Raffaele Scientific Institute, ${ }^{2}$ Stem Cell Research Institute (SCRI), and 3"Vita e Salute" San \\ Raffaele University, 20132 Milan, Italy, ${ }^{4}$ Department of Molecular Cell Biology, Max Planck Institute for Biophysical Chemistry, 37077 Goettingen, \\ Germany, ${ }^{5}$ Nina Ireland Laboratory of Developmental Neurobiology, Department of Psychiatry, University of California, San Francisco, San Francisco, \\ California 94158, and 'Laboratory of Regulation of Neuronal Development, Institute for Protein Research, Osaka University, Suita, Osaka 565-0871, Japan
}

The Arx transcription factor is expressed in the developing ventral telencephalon and subsets of its derivatives. Mutation of human ARX ortholog causes neurological disorders including epilepsy, lissencephaly, and mental retardation. We have isolated the mouse Arx endogenous enhancer modules that control its tightly compartmentalized forebrain expression. Interestingly, they are scattered downstream of its coding region and partially included within the introns of the downstream PolA1 gene. These enhancers are ultraconserved noncoding sequences that are highly conserved throughout the vertebrate phylum. Functional characterization of the Arx GABAergic enhancer element revealed its strict dependence on the activity of Dlx transcription factors. Dlx overexpression induces ectopic expression of endogenous Arx and its isolated enhancer, whereas loss of Dlx expression results in reduced Arx expression, suggesting that Arx is a key mediator of Dlx function. To further elucidate the mechanisms involved, a combination of gain-of-function studies in mutant $A r x$ or Dlx tissues was pursued. This analysis provided evidence that, although Arx is necessary for the Dlx-dependent promotion of interneuron migration, it is not required for the GABAergic cell fate commitment mediated by Dlx factors. Although Arx has additional functions independent of the Dlx pathway, we have established a direct genetic relationship that controls critical steps in the development of telencephalic GABAergic neurons. These findings contribute elucidating the genetic hierarchy that likely underlies the etiology of a variety of human neurodevelopmental disorders.

Key words: basal forebrain; development; epilepsy; GABAergic neuron; neuronal progenitor cell; basal ganglia

\section{Introduction}

During telencephalon development, tissue patterning and cell type specification are tightly connected processes that allow the emergence of neural structures coupled with specific cell-type composition. In fact, early on in development, glutamatergic and GABAergic cell fate specification is spatially confined into two nonoverlapping areas, namely, the dorsal pallium and the ventral subpallium, respectively. Despite the identification and characterization of numerous molecular players (mainly using a lossof-function approach), how their interactions are finely regulated and sequentially determined still remains unclear

\footnotetext{
Received March 25, 2008; revised June 30, 2008; accepted Aug. 16, 2008.

This work was supported by Telethon (GGP07181), Italian Ministry of Research (Investment Fund for Basic Research project), and "Ricerca Finalizzata-ex Art.56" Italian Ministry of Health (V.B.); Nina Ireland, Human Frontiers Science Program, and National Institute of Mental Health Grants R01 MH49428-01 and K05 MH065670 (J.L.R.R.); Max Planck Society and National Institutes of Health Beta Cell Biology Consortium (U19 DK072495-01) (A.M., P.C.); and Dr. H. Storz and Alte Leipziger Foundation (A.M.). We thank Drs. V. Pachnis, J. Briscoe, J. Gécz, and A. Fairen for sharing reagents and materials. We are grateful to Dr. V. Zappavigna for stimulating discussion. Elisabetta Feretti and Massimiliano Golino are acknowledged for advice on EMSA and initial cloning work, respectively.

*G.C. and P.C. contributed equally to this work.

Correspondence should be addressed to Vania Broccoli, Stem Cell Research Institute (SCRI), San RaffaeleScientific Institute, Via Olgettina 58, 20132 Milan, Italy. E-mail: broccoli.vania@hsr.it.

P. Collombat's present address: Inserm U636, F-06108 Nice, France.

DOI:10.1523/JNEUROSCI.1283-08.2008

Copyright $\odot 2008$ Society for Neuroscience $\quad$ 0270-6474/08/2810674-13\$15.00/0
}

(Guillemot, 2005, 2007). To address this crucial issue, the identification of the endogenous regulatory sequences controlling the temporal-spatial activities of these factors is a prerequisite to identify the mechanisms underlying gene regulation and specification of the different neural tissues.

Dlx1 and Dlx2 are homeodomain-containing transcription factors highly similar and redundant that act as critical molecular determinants of forebrain development. In the telencephalon, Dlx $1 / 2$ expression is restricted to the subventricular zone (SVZ) and mantle regions of the subcortical structures (Panganiban and Rubenstein, 2002). Dlx1/2 mouse mutants exhibit a block in the differentiation of progenitors located in the basal ganglia that was associated with a failure in neuronal tangential migration to the cerebral cortex, olfactory bulb, and hippocampus (Anderson et al., 1997a,b; Bulfone et al., 1998; Pleasure et al., 2000; Long et al., 2007). Furthermore, Dlx1/2 mutant cells exhibit exuberant neuritic growth and premature activation $\mathrm{p} 21$-activated serine/threonine kinase PAK3 (Cobos et al., 2007). These data suggest that the Dlx genes are, therefore, required for coordinating the timing of GABAergic cell migration and process formation.

How Dlx1/2 controls these key processes in telencephalon development and which molecular signals lie downstream to these factors is poorly understood. The Dlx1 and Dlx2 genes are located in a tail-to-tail oriented cluster with an intergenic region 


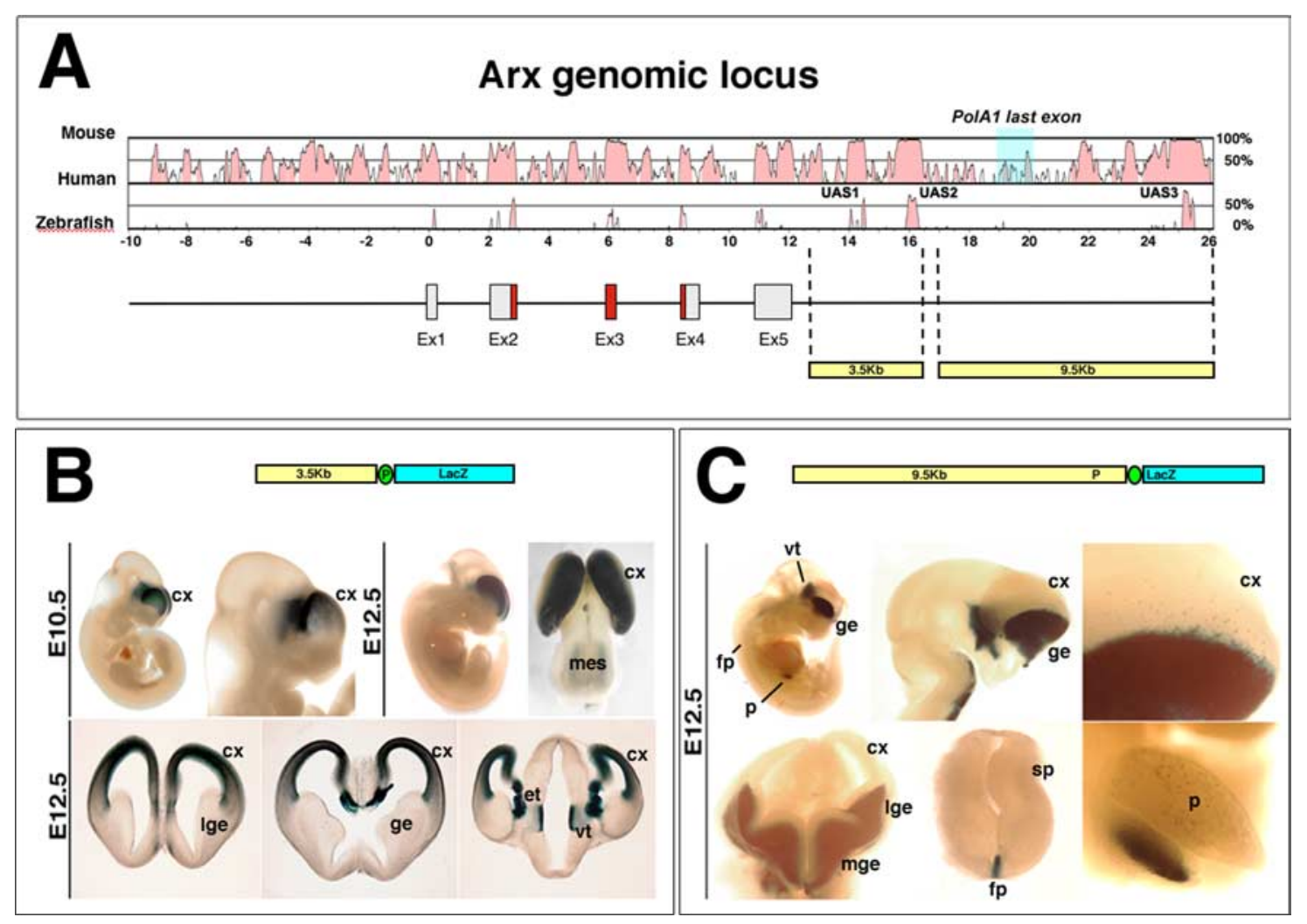

Figure 1. Characterization and identification of the genomic regions acting as Arx endogenous enhancers. $A$, VISTA genome browser schematic representation of nucleotide homology of $\sim 36$ $\mathrm{kb}$ of the Arx genomic locus in mouse, human, and zebrafish. Only three different genomic regions showed homology $>50 \%$ outside the transcribed sequences, and all were placed in the $3{ }^{\prime}$ region downstream to the coding sequences. In light blue is represented the sequence corresponding to the PolA1 last exon. Rectangles outline Arx coding exons, with red rectangles corresponding to homeodomain coding sequences. Yellow bars highlight the two genomic regions of 3.5 and $9.5 \mathrm{~kb}$ initially isolated to produce transgenic embryos. $\boldsymbol{B}$, E10.5 and E12.5 transgenic mice carrying the $3.5 \mathrm{~kb}$ proximal sequence upstream to the LacZ reporter gene. $\beta$-Galactosidase activity was confined to the developing cerebral cortex (cx), eminentia thalami (et), and vt (5/5 embryos analyzed). C, The $9.5 \mathrm{~kb}$ sequence targets expression of the reporter in the ge, vt, floor plate (fp), and pancreas (p) in E12.5 mouse transgenic embryos ( $4 / 4$ embryos analyzed). mes, Mesencephalon; sp, spinal cord.

that contains two conserved domains acting as enhancers for both genes (Ghanem et al., 2003). Specifically, within the I12b enhancer, controlling the expression of $D l x 1 / 2$ in the forebrain, a conserved E-box sequence was proved to specify the expression of $D l \times 1 / 2$ in the subpallium by associating with the basic helixloop-helix protein Mash1 (Ghanem et al., 2007; Poitras et al., 2007). Along the same line, Fode et al. (2000) demonstrated that Mash1 ectopic expression in the cortical primordium induces the expression of Dlx1/2. These data provided compelling evidence that $D l x 1$ and $D l \times 2$ genes represent direct targets of Mash1 in vivo. However, the detection of additional transcription factorbinding sites within the I12b enhancer (Poitras et al., 2007), such as Meis1/2-binding sites, indicates that additional transcriptional factors also control $D l \times 1 / 2$ expression. In addition, downstream factors that may mediate the regulation of subpallium development and GABAergic cell fate commitment and migration by Dlx1/2 are just beginning to be identified.

Arx encodes for a homeodomain-containing transcription factor belonging to a small family of mammalian homologs of the aristaless (al) Drosophila gene (Campbell et al., 1993; Miura et al., 1997; Meijlink et al., 1999). Mutations in the human ARX gene have been identified in a large variety of neuropathological conditions, including West and Partington syndromes, myoclonic epilepsy, lissencephaly, and nonsyndromic mental retardation (Kato et al., 2004; Gécz et al., 2006; Nawara et al., 2006). Both neuropathological studies in autoptic human tissues and analysis in Arx mutant animals provided evidence that Arx is necessary for the proper migration of subpallial neuronal progenitors to the cerebral cortex, and thus for the supply of the majority of GABAergic cortical interneurons (Bonneau et al., 2002; Kitamura et al., 2002; Colombo et al., 2007). Therefore, it has been suggested that, although these ARX-dependent pathological manifestations were thought to emanate from different molecular origins, they may all be included in a unique large class of neuropathological conditions known as "interneuronopathies" (Kato and Dobyns, 2005; Kato, 2006).

The Arx murine ortholog is expressed in the subpallium of the developing telencephalon both in the medial ganglionic eminence (MGE) and lateral ganglionic eminence (LGE), anterior entopeduncular region, anterior preoptic area, and the preoptichypothalamic region. Furthermore, Arx expression is maintained in the subpallial neurons migrating tangentially toward the cerebral cortical primordium (Kitamura et al., 2002; Colombo et al., 2004; Cobos et al., 2005a; Yoshihara et al., 2005). We previously demonstrated that Dlx factors control Arx activity (Cobos et al., 2005). However, it is unclear whether Arx represents a direct target of the Dlx proteins; furthermore, it is unknown what aspects of Dlx function are controlled by Arx. To investigate these issues, we identified the regulatory sequences that promote $A r x$ 's expression in forebrain GABAergic neurons. We then found that Dlx protein activity, both in vitro and in vivo, positively regulated this enhancer. Furthermore, using a combination of loss- and gain-of-function approaches, we provide evidence that Arx is not implicated in mediating the Dlx-dependent specification of GABAergic neuronal cells, whereas Arx does participate in regulating the Dlx-dependent GABAergic migration. 


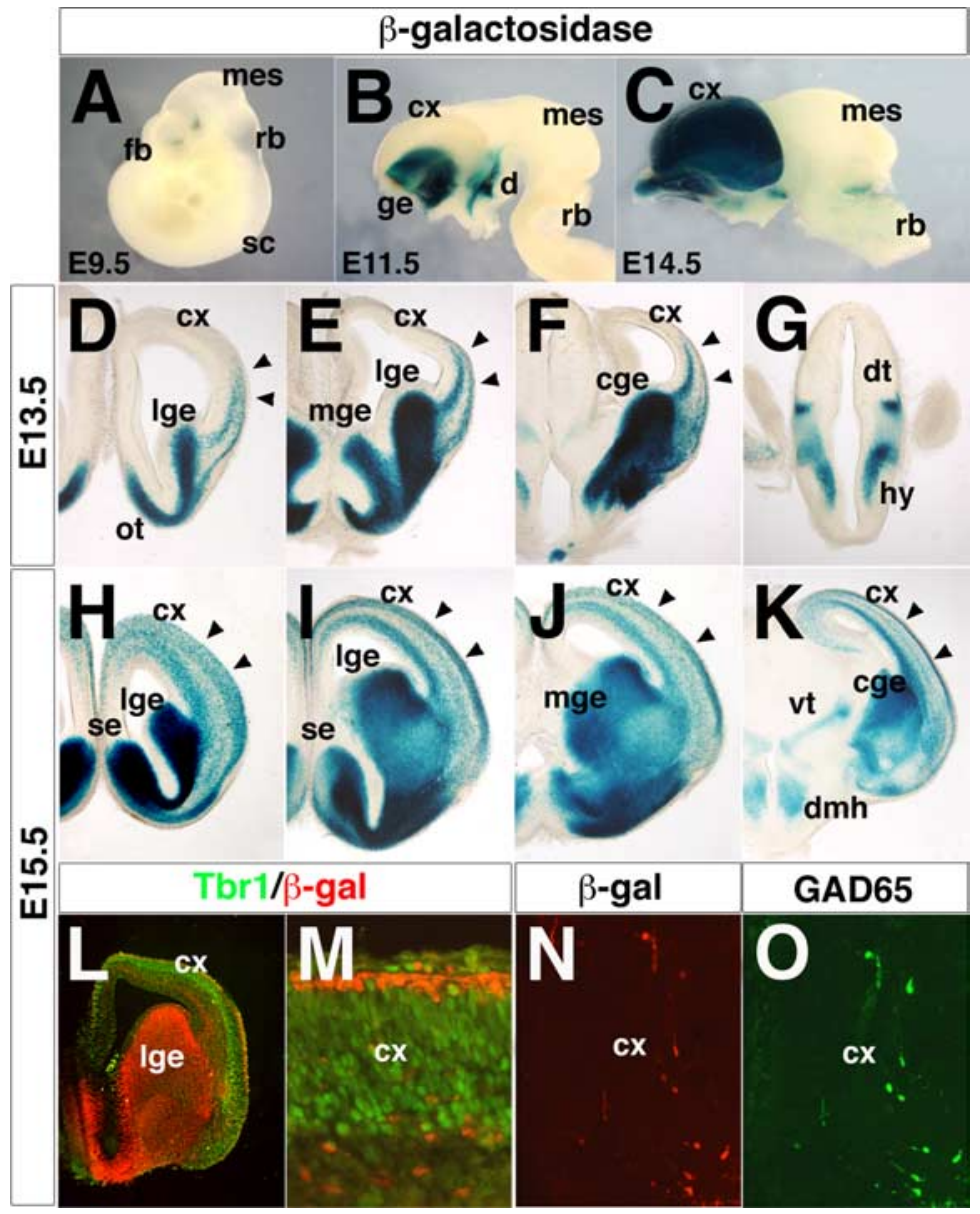

Figure 2. Analysis of the $\beta$-galactosidase activity profile during development in the $0.8 \mathrm{~kb}$ transgenic mouse line. $\boldsymbol{A}-\boldsymbol{C}$, Whole embryo at $E 9.5(\boldsymbol{A})$ and dissected brains at E11.5 $(\boldsymbol{B})$ and E14.5 $(\boldsymbol{C})$ showing reporter gene activity in the ge and diencephalons (d). $\boldsymbol{D}-\boldsymbol{K}$, Coronal vibratome sections of E13.5 (D-G) and E15.5 $(\boldsymbol{H}-\boldsymbol{K})$ showing $\beta$-galactosidase activity principally localized in the medial and lateral ganglionic eminences and in cells migrating toward the cortex following tangential deep and superficial streams (arrowheads in $\mathbf{D}-\boldsymbol{K}$ ). $\mathbf{L}-\mathbf{0}$, Stainings for $\beta$-galactosidase (red) and Tbr1 (green), a molecular marker for glutamatergic neurons, do not show any colabeled cells in the cerebral cortex $(\boldsymbol{L}, \boldsymbol{M})$; on the contrary, most of the $\beta$-galactosidase cortical cells were GAD65 positive, indicating a GABAergic cell fate $(\boldsymbol{N}, \mathbf{0})$. cge, Caudal ganglionic eminence; $c x$, cerebral cortex; dmh, dorsalmedial hypothalamic nucleus; dt, dorsal thalamus; fb, forebrain; hy, hypothalamus; mes, mesencephalon; rb, rhombencephalon; sc, spinal cord; se, septum.

\section{Materials and Methods}

Animals. Arx mutant mice (Collombat et al., 2003) and Dlx1/2 mutant mice (Qiu et al., 1997) were maintained by backcrossing with C57BL/6 animals. Genotyping was performed by morphological assessment [when possible, after embryonic day 13.5 (E13.5)] and confirmed by genomic PCR. Mice were maintained at San Raffaele Scientific Institute Institutional mouse facility, and experiments were performed in accordance with experimental protocols approved by local Institutional Animal Care and Use Committees.

Generation of transgenic mice. Genomic fragments were subcloned in the p1230 vector containing a $\beta$-actin minimal promoter followed by a LacZ reporter cassette. Transgenic mice were produced by pronuclear injection in FVB fertilized oocytes using standard procedures. Presence of the transgene was determined by PCR on DNA prepared from extraembryonic tissues of embryos or clipped tails of postnatal animals. For each construct, at least three founders or primary transgenic embryos were analyzed. Founder transgenic mice were maintained by breeding with FVB inbred animals and/or with CD1 outbred mice once it was assessed that transgene expression was no altered.

$X$-gal staining and immunohistochemistry. For immunoperoxidase staining, $10-\mu \mathrm{m}$-thick frozen sections were treated with $3 \%$ hydrogen peroxidase in methanol for $30 \mathrm{~min}$ at room temperature. Sections were rehydrated and blocked in $10 \%$ fetal calf serum, $0.5 \%$ bovine serum albumin (BSA) in PBS for $1 \mathrm{~h}$. Primary antibodies were diluted in the same medium, applied to sections and incubated overnight at $4^{\circ} \mathrm{C}$. Then, the slices were washed and incubated with appropriate biotinylated secondary antibody (DakoCytomation) for $90 \mathrm{~min}$. After washing, the sections were processed with a Vectastain ABC kit (Vector Laboratories) for $1 \mathrm{~h}$ at room temperature and revealed with DAB peroxidase substratum (SK4100; Vector Laboratories). Finally, sections were dehydrated, dried, and coverslipped with Eukitt (Electron Microscopy Science).

The primary antibodies used were as follows: mouse anti-MAP2 (1:400; Millipore Bioscience Research Reagents), rabbit anti-NPY (1:1000; Incstar), rabbit anti-calretinin (1:1000; Swant), rabbit anti-DARPP32 (1:50; Immunological Sciences), rabbit anti-ChAT (1:500; Millipore Bioscience Research Reagents). For immunofluorescence, secondary antibodies of the Alexa family were used (Invitrogen) in combination with the fluorescent dye Hoechst 33342 (Invitrogen). Then, slices were washed and mounted in Fluorescent Mounting Medium (DakoCytomation).

Hippocampal primary neuronal cultures. Primary neuronal cultures were prepared from the hippocampi of Sprague Dawley E18 rat embryos (Charles River) as described previously (Banker and Cowan, 1977). Briefly, hippocampi were dissected in ice-cold HBSS supplemented with antibiotics and incubated in $0.25 \%$ trypsin at $37^{\circ} \mathrm{C}$ for $15 \mathrm{~min}$. Cell dissociation was performed using polished glass pipettes until obtaining a single-cell suspension. Neurons were plated on poly-lysine-treated coverslips. After $4 \mathrm{~h}$, coverslips were moved to Petri dishes with cultured glial cells and cultured in MEM supplemented with 1\% N2 supplement (Invitrogen), 2 mm glutamine (BioWhittaker), $0.1 \%$ ovalbumin, $1 \mathrm{~mm}$ sodium pyruvate (Sigma-Aldrich), and $4 \mathrm{~mm}$ glucose. Neurons were cultured up to $15 \mathrm{~d}$ at $37^{\circ} \mathrm{C}$ in a $5 \% \mathrm{CO}_{2}$ atmosphere, changing half of the medium every other day.

Transient cotransfection experiments. Transient cotransfection studies were performed on P19 murine embryonic carcinoma cells cultured in $\alpha$-MEM, 10\% FBS, penicillin/streptomycin, and essential amino acids. Cells $(300,000)$ were seeded in six-well plates and transfected with the Lipofectamine reagent (Invitrogen) using $10 \mu \mathrm{g}$ of luciferase reporter plasmid, $5 \mu \mathrm{g}$ of expression construct, and $2 \mu \mathrm{g}$ of pRSV- $\beta$-galactosidase as an internal control of transfection efficiency. Cells were harvested $36-48 \mathrm{~h}$ after transfection, lysed incubating in ice for $10 \mathrm{~min}$ in lysis buffer (25 mм Gly-Gly, pH 7.8, 15 mm $\mathrm{MgSO}_{4}, 4$ mм EGTA, 1 mм DTT, and $1 \%$ Triton X-100) and centrifuged at $4^{\circ} \mathrm{C}$ for $15 \mathrm{~min}$. Cell extracts were subjected to luciferase and $\beta$-galactosidase assays as described previously (Zappavigna et al., 1994).

Electrophoretic mobility shift assays. Oligonucleotides corresponding to the Dlx putative binding sites were labeled by T4 kinase reactions in the presence of radiolabeled $\gamma^{32} \mathrm{P}$-ATP (GE Healthcare). Electrophoretic mobility shift assays (EMSAs) were performed with in vitro-translated proteins as previously described using $2 \mu \mathrm{l}$ of reticulocyte lysate containing the desired combination of proteins mixed with $18 \mu \mathrm{l}$ of PPH binding buffer [10 mm Tris-Cl, pH 7.5, 75 mm NaCl, 1 mm EDTA, 6\% glycerol, 3 $\mathrm{mm}$ spermidine, $1 \mathrm{~mm}$ dithiothreitol, $0.5 \mathrm{~mm}$ phenylmethylsulfonyl fluoride (PMSF), $1 \mu \mathrm{g}$ of poly(dI-dC), 30,000 cpm ${ }^{32} \mathrm{P}$-labeled oligonucleotide] to a total volume of $20 \mu \mathrm{l}$. After $30 \mathrm{~min}$ of incubation on ice, the 
reaction mixtures were separated by $5 \%$ PAGE in $0.5 \times$ Tris-buffered EDTA. For the competition assays, a 50 - or 100-fold molar excess of unlabeled competitor oligonucleotide was added to the binding reaction mixture $10 \mathrm{~min}$ before the labeled probe.

Chromatin immunoprecipitation. E13.5 mouse embryonic forebrains were isolated and single-cell suspension derived by enzymatic treatment. Cells were cross-linked with $1 \%$ formaldehyde for $10 \mathrm{~min}$ and chromatin prepared essentially as described previously (Ferrai et al., 2007) by using 10 sonication cycles [ $35 \mathrm{~s}$ at $60-70 \mathrm{~W}$, in an Ultrasonic Processor XL Sonicator (Misonix), followed by a 2 min rest on ice]. Cross-linked chromatin-containing fractions were pooled and stored at $-80^{\circ} \mathrm{C}$. Each aliquot of cross-linked chromatin $(55 \mu \mathrm{g})$ was precleared with $17.5 \mu \mathrm{l}$ of Protein A-Sepharose beads (GE Healthcare), previously coated with $10 \mu \mathrm{g} / \mathrm{ml}$ each of poly-(dI-dC), poly-(dG-dC), and poly-(dA-dT) and with $100 \mu \mathrm{g} / \mathrm{ml} \mathrm{BSA}$ in RIPA buffer ( $1 \mathrm{~mm}$ EDTA, 0.5 mM EGTA, 10 mu Tris, pH 8, $1 \%$ Triton X-100, $0.1 \%$ Na deoxycholate, $0.1 \%$ SDS, $140 \mathrm{~mm} \mathrm{NaCl}$, and $1 \mathrm{~mm}$ PMSF). The aliquots were then incubated overnight with $1 \mu \mathrm{g}$ of the appropriate antibodies in a total volume of $1 \mathrm{ml}$ of RIPA buffer and immunoprecipitated as described previously (Ferrai et al., 2007). After immunoprecipitation, the material was treated with RNase A $(50 \mu \mathrm{g} / \mathrm{ml})$ for $30 \mathrm{~min}$ at $37^{\circ} \mathrm{C}$ and by proteinase $\mathrm{K}(500$ $\mu \mathrm{g} / \mathrm{ml})$ in $0.5 \%$ SDS at the same temperature overnight. Formaldehyde cross-links were reverted by heating the samples at $65^{\circ} \mathrm{C}$ for $6 \mathrm{~h}$, and the DNA was purified with phenol extraction and resuspended in $200 \mu \mathrm{l}$ of distilled water. Resuspended material $(4 \mu \mathrm{l})$ was used as a template in PCRs. PCR primers used are the following: mArx-F2, 5'-GTCTATAAGTACAATGGTGACAC-3'; mArx-R2, 5' -CTCCATCAAGATCCTTCTC-3' (amplification product, 240 bp); interleukin- $1 \beta$ (IL-1 $\beta$ )-F, $5^{\prime}$-ACCTATCTTCTTCGACACATGGG- $3^{\prime}$; IL- $1 \beta$-R, 5'-GGGCTTATCATCTTTCAACACGC-3' (amplification product $200 \mathrm{bp}$ ). PCR primers for Neuropilin-2 (Npn2) regulatory sequences were used as described by Le et al. (2007). PCR products were analyzed on $2 \%$ agarose gels in $0.5 \times$ TBE buffer. The specific antibodies used for immunoprecipitations were against acetylated histone $\mathrm{H} 3$ (\#06-599; Millipore) and Dlx proteins (Kuwajima et al., 2006). For mock controls, chromatin was immunoprecipitated either without antibody or with an unrelated polyclonal antibody against uPAR (urokinase-type plasminogen activator receptor) generated in the laboratory of Prof. Blasi (San Raffaele Scientific Institute, Milan, Italy) (Ferrai et al., 2007).

Organotypic culture, electroporations, and grafting experiments. Slice cultures of embryonic mouse forebrain were prepared as described previously (Anderson et al., 1997b). Briefly, mouse brains were isolated and embedded in $4 \%$ low-melting agarose (Sigma-Aldrich), and $250-\mu \mathrm{m}$ thick coronal sections were cut on a vibratome. The sections were then transferred to polycarbonate culture membranes (diameter, $13 \mathrm{~mm}$; pore size, $8 \mu \mathrm{m}$; Costar) in organ tissue dishes containing $1.5 \mathrm{ml}$ of serumcontaining medium (Invitrogen $\alpha$-MEM with $10 \%$ fetal calf serum, glutamine, penicillin, and streptomycin). Slices were maintained for $1 \mathrm{~h}$ at $37^{\circ} \mathrm{C}$ in $5 \% \mathrm{CO}_{2}$ in a standard sterile incubator. Before changing to the Neurobasal/B27 (Invitrogen) medium, sections were electroporated with a square electroporator (ECM830; BTX) using planar electrodes (BTX) as described by Stühmer et al. (2002). Two $5 \mathrm{~ms}$ electric pulses of $100 \mathrm{~V}$ were applied to targeting one side of the section. In those cases in which cell migration from MGE needed to be assessed, the day after electroporation the targeted MGE was carefully isolated and transplanted into the homologous region in the contralateral side of the same sections. After grafting, slices were cultured up to $48 \mathrm{~h}$.

Statistics. Results were expressed as mean value \pm SD and were tested for statistical significance by the one-tailed Student's $t$ test for paired differences with GraphPad Prism software.

\section{Results}

Identification of genomic regions controlling Arx activity

The Arx gene exhibits a fairly elaborated expression pattern: during embryonic development, it is detected in different organs and 


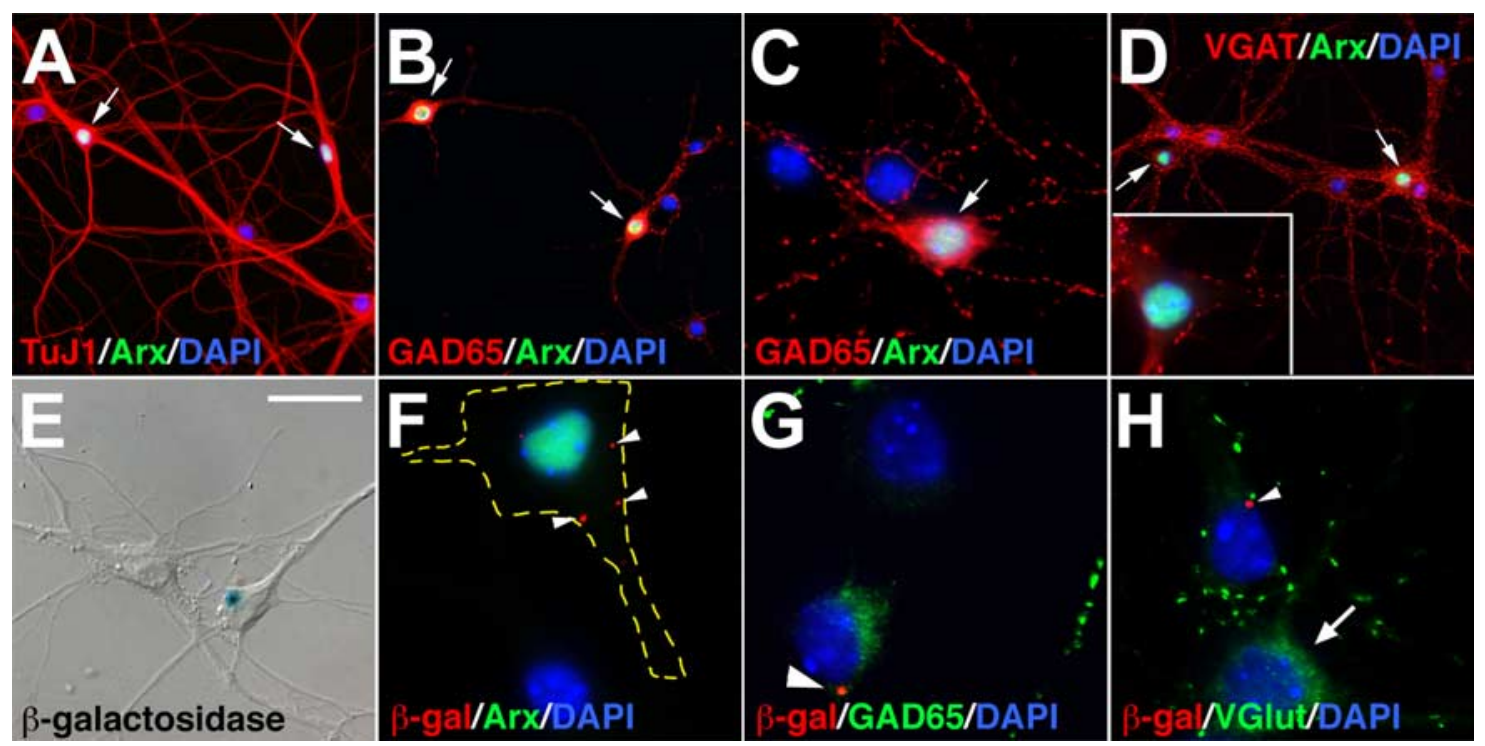

Figure 4. Single-cell resolution labeling of embryonic hippocampal neuronal neurons (10-14 d in vitro) from wild-type or $0.8 \mathrm{~kb}$ transgenic mice. $A-D$, Cell fate analysis of Arx-positive cells from wild-type animals. Arx colocalizes with the general neuronal marker TuJ1 $(\boldsymbol{A})$ and with the markers of GABAergic neurons GAD65 (B, $\boldsymbol{C}$ ) and VGAT (D). $\boldsymbol{D}$, Inset, A high-magnification image highlighting Arx nuclear staining. $\boldsymbol{E}-\boldsymbol{H}, \boldsymbol{\beta}$-Galactosidase + cells are also labeled by antibodies against Arx $(\boldsymbol{F})$ or GAD65 (G), but not by the Vglut1 antibody, specific for glutamatergic neurons $(\boldsymbol{H})$. In $\boldsymbol{E}$, the localization of $\beta$-galactosidase activity is shown in blue by differential interference contrast. Arrows in $\boldsymbol{A}-\boldsymbol{D}$ point at somata of neurons. Arrowheads in $\boldsymbol{F}$ - $\boldsymbol{H}$ indicate red dots corresponding to sites of accumulation of $\beta$-galactosidase, whereas arrow in $\boldsymbol{H}$ points at the soma of a Vglut $1+$ neuron, where $\beta$-galactosidase is absent. The broken lines in $\boldsymbol{F}$ outline the edge of a neuron positive for $\beta$-galactosidase (identified by differential interference microscopy).

tissues such as brain, floor plate, somites, pancreas, and gonads. In particular, in the CNS, its expression has been described in different regions, including the ventral thalamus, eminentia thalami, medial and lateral ganglionic eminences, and cerebral cortex (Miura et al., 1997; Bienvenu et al., 2002; Kitamura et al., 2002; Strømme et al., 2002; Colombo et al., 2004; Poirier et al., 2004; Yoshihara et al., 2005). Furthermore, within these neural compartments, Arx was found to act at different stages of differentiation. In fact, whereas in the cerebral cortex Arx is selectively expressed in the ventricular zone (VZ) proliferating cells, in the basal ganglia, most Arx-positive cells correspond either to proliferating SVZ neuroblasts or to postmitotic young neurons (Colombo et al., 2004; Cobos et al., 2005a).

Therefore, to understand how this complex temporal and spatial expression profile was achieved, we sought to search the cisregulatory elements controlling Arx expression in the brain. We first performed a multiple phylogenetic alignment of genomic DNA including the Arx gene locus and its flanking regions using the VISTA browser tool (http://genome.lbl.gov/vista). This analysis compared orthologous sequences from human, mouse, and zebrafish genomes. Beside a reasonable nucleotide conservation of exonic sequences, this search highlighted three small domains localized downstream of the Arx gene and exhibiting a nucleotide conservation $>50 \%$ (Fig. $1 A$ ). These three domains were termed ultraconserved Arx sequence 1 (UAS1), UAS2, and UAS3. In particular, UAS1 is $651 \mathrm{bp}$ long and located $3.7 \mathrm{~kb}$ downstream to Arx poly-A signal (ChrX: 90,546,954-90,547,604; UCSC Genome Browser), UAS2 is a 328 sequence placed $5.1 \mathrm{~kb}$ downstream (ChrX: $90,548,333-90,548,660)$ and, finally, UAS3 is 811 bp long and located 12.6 kb distally (ChrX: 90,555,532-90,556,342).

Remarkably, UAS3 was found included within the last intron of the PolA1 gene, coding for the DNA polymerase $\alpha 1$. Both genes display a tail-to-tail orientation with the last exon of PolA1 being located $6.8 \mathrm{~kb}$ downstream of the Arx coding region. Conversely, we did not detect sufficient nucleotide conservation among the different species in the region spanning the $10 \mathrm{~kb}$ upstream to the Arx initiation codon (Fig. $1 A$ ).

To uncover putative cis-regulatory elements, the $13.5 \mathrm{~kb}$ genomic DNA located downstream of the Arx gene was split into two fragments of 3.5 and $10 \mathrm{~kb}$, the first encompassing UAS1 and UAS2, and the second containing UAS3. Both sequences were cloned upstream of a minimal $\beta$-actin promoter followed by the $L a c Z$ reporter gene. Transgenic animals were generated and analyzed for $\beta$-galactosidase activity. In five different transgenic embryos, the $3.5 \mathrm{~kb}$ sequence was found able to specifically direct LacZ expression in the developing cerebral cortex, eminentia thalami, and ventral thalamus (Fig. $1 B$ ). Conversely, the $10 \mathrm{~kb}$ fragment was able to drive reporter expression in the developing basal ganglia, ventral thalamus, floor plate, and pancreas anlage, as tested in four different transgenic embryos (Fig. 1C). These results demonstrated that the two genomic fragments were able to target reporter expression in domains normally expressing the Arx gene. Interestingly, these two sequences were also found capable of independently targeting LacZ expression and recapitulating two complementary Arx-expressing domains. These findings indicate that $A r x$ expression relies on at least two different regulatory elements that may operate independently from each other.

\section{Characterization of the UAS3-mediated spatial-temporal expression profile}

To determine in vivo whether the UAS3 sequence, present within the last Pola1 intron, could act as cis-acting regulatory element controlling Arx expression, we designed reporter constructs encompassing a $0.8 \mathrm{~kb}$ UAS3-containing DNA fragment and generated transgenic mice. Two stable mouse lines were characterized and found to exhibit identical expressions of the reporter gene. $\beta$-Galactosidase activity was first detected at E9 in the diencephalon and, starting from E10, in the ganglionic eminences (ge), where the expression of the reporter was found maintained during further development (Fig. 2A,B). 
In E13.5 coronal brain sections, a strong labeling was observed in the olfactory tubercle (ot), LGE, MGE, caudal ganglionic eminence, ventral thalamus (vt), and hypothalamus (Fig. 2D-G). Transgene expression appeared undetectable in the ventricular regions of these structures, in agreement with the Arx expression pattern previously reported in the SVZ and mantle zone, but not in the proliferative periventricular areas (Miura et al., 1997; Colombo et al., 2004; Cobos et al., 2005a). Interestingly, two main streams of tangentially migrating cells starting from the ventral basal ganglia were highlighted (Fig. $2 D-F)$. This observation is consistent with the dynamics of migration of GABAergic cortical interneuron precursors originating from the ventral pallium (Corbin et al., 2001; Marín and Rubenstein, 2001; Métin et al., 2006; Wonders and Anderson, 2006). Similar to interneurons, by E15.5, numerous LacZ-positive cells seemed to have reached the dorsal pallium as three large streams invading the cortical subventricular region and intermediate and marginal zones (Fig. $2 \mathrm{H}-\mathrm{K}$, arrows in $I$ ). To ascertain the identity of LacZ-labeled cells, an immunofluorescent analysis was performed using antibodies raised against markers of glutamatergic or GABAergic neurons, such as Tbr1 and GAD65, respectively. Although $\beta$-galactosidase-labeled cells were found negative for Tbr1, virtually all expressed GAD65, identifying these unambiguously as GABAergic cortical interneurons (Fig. 2L-O). Therefore, the UAS3 genomic element appears to induce both transgene expression dynamics and cell type-specific localization, in a manner closely recapitulating Arx expression pattern in the forebrain.

Arx expression is maintained in postnatal stages and in the adult brain in the rostral migratory stream, neurons of the olfactory bulbs, and GABAergic cortical interneurons (Colombo et al., 2004). Hence, we wondered whether the UAS3 genomic element could also control Arx expression postnatally. Reporter gene expression was detected in adult brains of both transgenic lines. In particular, $\beta$-galactosidase activity was found localized in cells of the olfactory bulbs (Fig. 3A), rostral migratory stream (Fig. 3B), cerebral cortex (Fig. 3C), striatum, septum (Fig. 3D), ventral thalamus (Fig. $3 E$ ), reticular thalamic nucleus (Fig. $3 E$ ), dorsalmedial hypothalamic nucleus (Fig. $3 F$ ), and telencephalic subventricular region (Fig. 3G). Thus, this spatial distribution of the enhancer activity closely matched the described Arx endogenous expression profile (Colombo et al., 2004; Yoshihara et al., 2005). $\beta$-Galactosidase labeling provides an informative resolution mapping of the Arx expression pattern at a single-cell level. Therefore, transgene-positive cortical cells were assayed for the expression of several markers for GABAergic neurons to determine which subclasses of interneurons UAS3 targets. Interestingly, we found that most, if not all, neurons belonging to the three main subsets of GABAergic interneurons identified by the nonoverlapping expression of parvalbumin, calretinin, and NPY and accounting for $\sim 80 \%$ of all the cortical interneurons were coexpressing the reporter gene (Fig. $3 \mathrm{H}-\mathrm{O}$ ). This finding was in agreement with previous observations regarding Arx expression in the adult cerebral cortex (Colombo et al., 2004). A thorough analysis was next performed using primary cultures of E18.5 wild-type and transgenic hippocampal neurons (Bonanomi et al., 2005). Arx was found present only in the neuronal fraction, but not in glial cells (Fig. 4A), and, in particular, appeared expressed selectively in most, if not all, isolated GABAergic neurons as demonstrated using the GABAergic markers GAD65 and vesicular GABA transporter (VGAT) (Fig. $4 B-D$, arrows). $\beta$-Galactosidase activity in primary neuronal cultures was detected as single dots in the cytoplasm of Arx-positive neurons (Fig. 4F, arrowheads). Furthermore, transgene activity was detected in a large fraction of GAD65+ neurons, but not Vglut1+ neurons, identifying GABAergic and glutamatergic neuronal populations, respectively (Fig. 4G,H, arrows). These findings imply that Arx and the reporter controlled by the UAS3 genomic element share a common expression profile in most of the mature cortical and hippocampal GABAergic interneurons. 


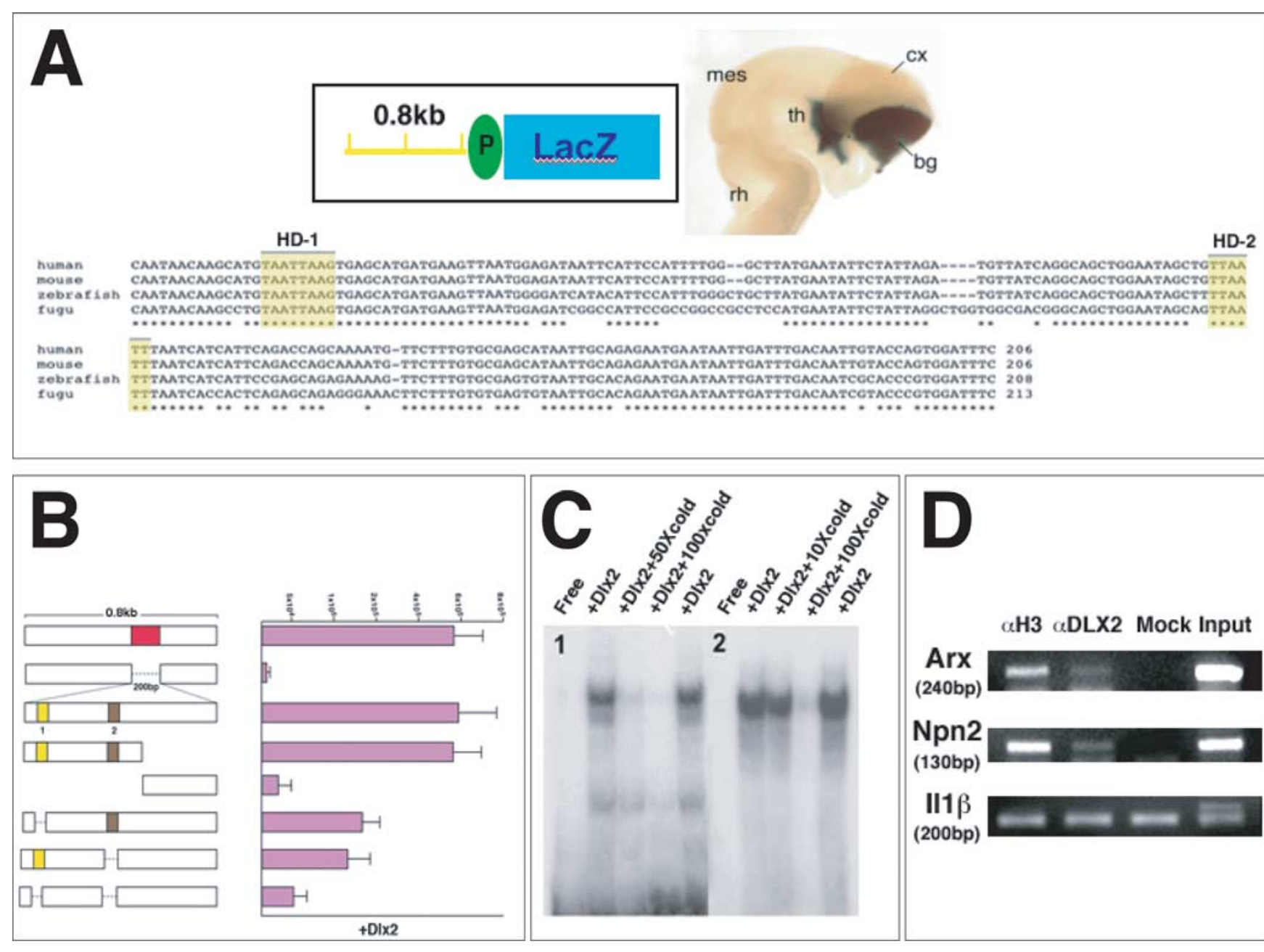

Figure 6. Identification of the mUAS enhancer core sequence and its dependence on Dlx2 activity. $A$, Phylogenetic comparison showing the high homology of an $\sim 200 \mathrm{nt}$ fragment included in the UAS3 sequence. Asterisks indicate conserved nucleotide residues. Two conserved binding sites for homeodomain proteins are highlighted in yellow and named HD-1 and HD-2.B, Both the entire $0.8 \mathrm{~kb}$ and $200 \mathrm{nt}$ sequences are strongly activated by Dlx2 in transient cotransfection assays in P19 cells, whereas a $0.8 \mathrm{~kb}$ sequence deprived of the $200 \mathrm{bp}$ fragment is not responding to Dlx 2 activity. A series of deletion constructs removing each single or both HD-1/2 binding sites (yellow and brown boxes, respectively) reveal their requirement for triggering the proper Dlx2-induced activity. Values shown represent the mean relative luciferase activity obtained by three independent experiments \pm SEM. C, EMSA using the HD- 1 and HD- 2 sequences shows a strong binding to a DIx 2 in vitro translated protein. Preincubation with an increasing amount of nonlabeled oligonucleotides abolishes the formation of the Dlx2-HD1 or Dlx2-HD2 complexes. D, Chromatin immunoprecipitation experiments showing Dlx2 binding to the mUAS3 sequence in vivo. PCR analysis was performed on the immunoprecipitated chromatin isolated from E14.5 ventral forebrain tissue using primers corresponding to the mUAS3 sequence (Arx) and Npn2 and IL-1 $\beta$ as positive and negative control genes, respectively. As negative control, immunoprecipitation was performed without antibody (Mock). As input, unprecipitated chromatin was used for amplifications. bg, Basal ganglia; cx, cerebral cortex; mes, mesencephalon; rh, rhombencephalon; th, thalamus.

Subsequently, the transgene expression in adult olfactory bulb and striatum was analyzed. A strong $\beta$-galactosidase staining was detected in the granular cell layer (gcl) and glomerular layer (gl) of the adult olfactory bulb (Fig. $5 A, B$ ). The glomerular layer represents the domain in which olfactory axons establish synaptic contacts with the primary dendrites of mitral and tufted projection neurons. Local interneurons surround the glomeruli and are thereby termed periglomerular cells. UAS3 element was found to target transgene expression both in GABAergic and dopaminergic periglomerular interneurons as shown by colabeling with GAD65, calbindin, and TH (Fig. 5C-H). Furthermore, $\beta$-galactosidase labeled a significant fraction of GABA + granular cells in the gcl (Fig. 5C,E). Conversely, transgene expression was not detected in olfactory escheating glia (NPY+) nor in glutamatergic mitral neurons (data not shown). Yet again, this expression pattern closely matched Arx protein distribution previously described in the adult olfactory bulbs (Yoshihara et al., 2005). Finally, UAS3-dependent expression was analyzed in the adult striatum. LacZ staining revealed only a few scattered positive cells in this structure (Fig. 5I). Colocalization experiments with the principal striatal spiny neuron marker DARPP32 or the striatal interneuron markers NPY or ChAT revealed a $\beta$-galactosidase coexpression only with the latter cell population (Fig. $5 J-L$ ). These findings indicate that the striatal UAS3 transgene expression became confined to GABAergic and cholinergic interneurons in adulthood.

\section{Molecular analysis of the UAS3 enhancer element}

To identify the minimal sequence acting as enhancer in the UAS3 domain, we performed a homology search (phylogenetic footprinting) in four different vertebrate species: human, mouse, zebrafish, and fugu (Fig. 6A). Only a stretch of $205 \mathrm{bp}$ in this entire domain revealed a high nucleotide conservation among the four species (from $100 \%$ to $91 \%$ when compared human to mouse and zebrafish, respectively). In contrast, identity in UAS3 sequences outside this core was generally much lower ( $42 \%$ human to zebrafish). We named the core element mUAS3, for minimal UAS3 enhancer sequence. The mUAS3 sequence was compared 
with a library of matrix descriptions for transcription-binding sites using the MatInspector software (Genomatix). By DNAbinding module selection and relevance to forebrain development, we chose to further analyze two $5^{\prime}$-TAATT-3' sites that we termed HD-1 and HD-2, which are highly conserved in all different sequences and are bound by homeodomain transcription factors. Although several different homeodomain proteins are normally expressed in the forebrain, only a few are localized in the ventral telencephalon. In particular, we considered as possible activators those expressed in the ganglionic eminences: Mash1, Nkx2.1, Gsh1/2, Pax6, Isl1, and Dlx1/2/5. To test these putative activators, expression vectors for each of these genes were cotransfected with a luciferase reporter gene controlled by the UAS3 element in P19 embryonal carcinoma cells. Importantly, we detected a dramatic increase in luciferase activity only in the presence of Dlx1/2/5, whereas a negligible expression was observed after cotransfecting all the other genes (Fig. $6 B$, data not shown). Therefore, despite the fact that mUAS3 element displayed a rather consensual homeodomain binding sequence, only Dlx proteins were able to consistently induce luciferase expression (Fig. 6B, data not shown). This transactivation ability was strongly reduced when the mUAS3 sequence was devoid of the two HD-1/2 sequences (Fig. $6 \mathrm{~B}$ ). Hence, despite the presence of few additional AT palindromic sequences in the UAS3 element, none appeared capable of sustaining Dlx2 activity in the absence of HD-1/2 elements. Next, to unambiguously confirm that Dlx2 interacts with the mUAS3 sequence, we first used EMSAs. Hence, DLX2 protein was translated in vitro and was indeed found able to directly bind to both sequences (Fig. 6C). Subsequently, to determine whether this interaction also occurred in vivo, we performed chromatin immunoprecipitation assays. As a positive control, we used a previously reported Dlx2binding sequence on the Npn2 promoter, whereas an IL- $1 \beta$ promoter element was chosen as unspecific sequence (Le et al., 2007). The chromatin was isolated from E14.5 mouse forebrains and precipitated with a highly specific Dlx2 antibody (Kuwajima et al., 2006). In all cases ( 3 of 3), only the Arx and Npn2, but not the IL-1 $\beta$, sequences were precipitated by the anti-Dlx 2 antibody, clearly indicating that Arx indeed is a reliable Dlx2 target gene during embryonic development. Finally, to verify whether the mUAS3 element itself can induce reporter activity in forebrain GABAergic tissue, we generated transgenic mice with multiple oligomerized mUAS3 sequences upstream of the $\beta$-galactosidase reporter. All founder embryos ( 5 of 5) displayed a tissue-specific $\beta$-galactosidase activity that overlapped with $A r x$ endogenous expression, although with a much weaker intensity than the UAS3 reporter activity (data not shown).

In vivo requirement of Dlx binding for UAS3 proper activity To reveal whether Dlx activity was sufficient to promote the UAS3 enhancer activity in vivo, we ectopically expressed Dlx2 either in the forebrain or the midbrain of E13.5 mouse brain slices. At first, we confirmed our experimental design demonstrating that Dlx2 misexpression was indeed able to activate Gad2 expression in the forebrain tissue as previously reported by Stühmer et al. (2002) (Fig. 7A-D). In addition to the forebrain, the exogenous Dlx2 also triggered GAD65 protein activation in the 


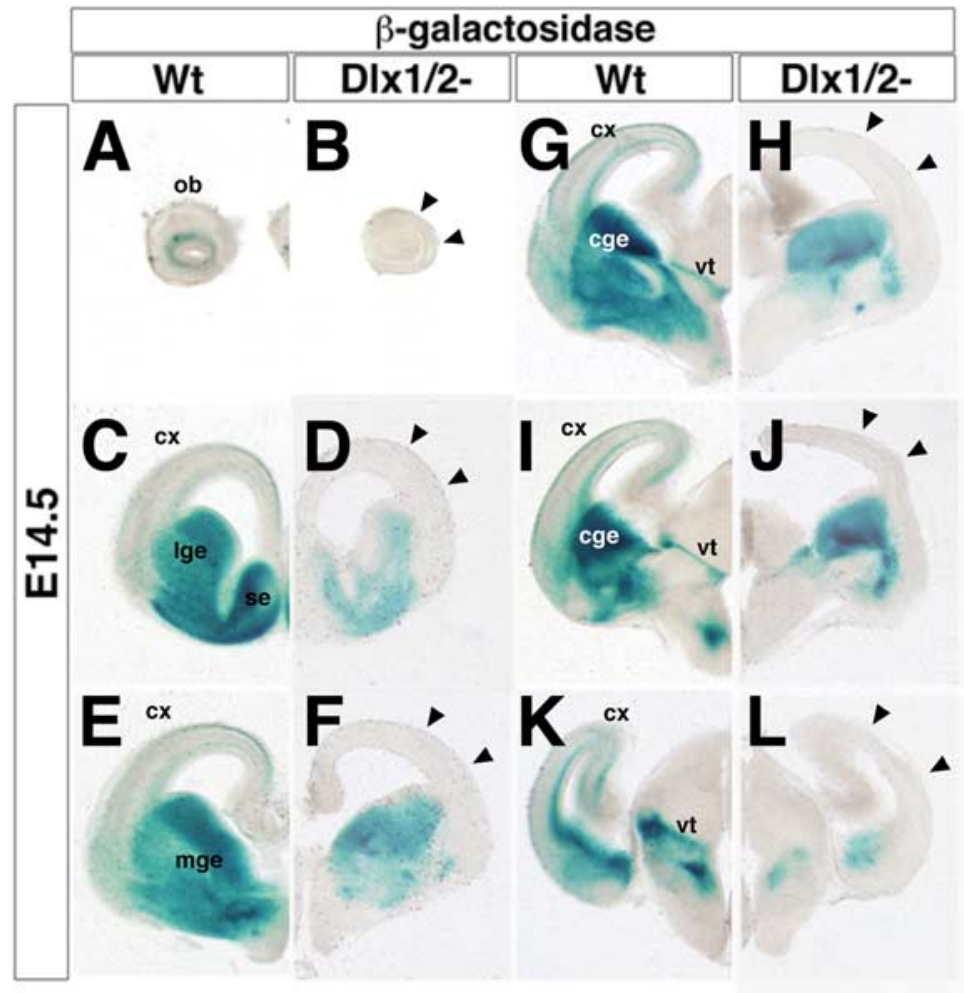

Figure 8. $\quad \beta$-Galactosidase activity in E14.5 brain sections of the Arx $0.8 \mathrm{~kb}$ transgenic mice in wild-type (Wt) or D/x1/2 mutant background. Sections on similar coronal levels are compared between wild-type (left side) and Dlx1/2 mutant (right side) genotypes. $\beta$-Galactosidase activity is reduced in $D / x 1 / 2$-deficient brain tissue. In these brains, reporter gene expression is marginally detectable in LGE, MGE, and vt $(\boldsymbol{D}, \boldsymbol{F})$. Conversely, $\beta$-galactosidase is still detectable, although reduced, in the mutant caudal ganglionic eminence $(\mathrm{cge})(\boldsymbol{H}, \boldsymbol{J}, \boldsymbol{L})$. DIx $1 / 2$ mutant tissues are devoid of any reporter staining in the cerebral cortex (cx), indicating a complete absence of $G A B A e r g i c$ neuronal migration from the ventral telencephalon (arrowheads in $\boldsymbol{B}, \boldsymbol{D}, \boldsymbol{F}, \boldsymbol{H}, \boldsymbol{J}, \boldsymbol{L}$ ), by contrast to wt tissue $(A, C, E, G, I, K)$. ob, Olfactory bulb; se, septum.

mesencephalon, a neural tissue in which GABAergic neuronal fate is normally controlled in a Dlx2-independent manner (Miyoshi et al., 2004; Guimera et al., 2006; Nakatani et al., 2007). We next assayed whether $\beta$-galactosidase expression was activated after Dlx 2 misexpression in brain slices of UAS 3 transgenic mice. Both in the cerebral cortex and the ventral mesencephalon, Dlx2 was found able to elicit the activation of the reporter gene with a virtually perfect correspondence between Dlx2misexpressing cells and LacZ ectopic expression (Fig. 7I-P). These results strongly indicate that Dlx2 mediates the activation of the UAS3 enhancer element controlling its spatiotemporal expression. If the UAS3 element represents the faithful Arx GABAergic enhancer, Dlx2 misexpression should trigger Arx endogenous expression in a similar manner. Indeed, using adjacent sections to those analyzed for UAS3-dependent $\beta$-galactosidase activity, Arx immunoreactivity was detected in all Dlx2misexpressing cortical and mesencephalic neurons. Altogether, these data suggest that Arx expression is regulated in vivo by Dlx2 activity most probably through the activation of the UAS3 enhancer.

To further characterize the UAS3-dependent Dlx activity, we crossed UAS3 transgenic mice with Dlx1/2 mutant animals and analyzed reporter activity in a $D l x 1 / 2$ null background. Interestingly, $\beta$-galactosidase activity was still detectable in these mice in MGE, LGE, and ventral thalamus, albeit to a much lower intensity than in controls. Conversely, $\mathrm{LacZ}$ gene expression was not strongly reduced in the caudal ganglionic eminences (Fig. $8 \mathrm{H}, \mathrm{J}$ ). Furthermore, reporter signal was excluded from the cerebral cortex because of the failure of GABAergic neurons to tangentially migrate in $D l \times 1 / 2$ mutants (Fig. $8 B, D, F$, $H, J, L$, arrows). These findings are in agreement with previous observations that revealed a still detectable, although strongly reduced, Arx mRNA expression in Dlx1/2 mutant mice (Cobos et al., 2005a).

Together, these results suggest that Dlx $1 / 2$ transcription factors are sufficient to control UAS3 activity expression profile in misexpression studies and are necessary for correct UAS3 activity. Moreover, Dlx1/2independent molecular mechanisms seem to act to maintain a detectable activity of the UAS3 element at least in some tissues expressing Arx.

\section{Arx modulates the Dlx-dependent migratory activity but not the ability of Dlx to specify the GABAergic cell fate}

Dlx1/2 transcription factors are critical throughout forebrain development. They play pleiotropic functions in regulating ventral forebrain structures and GABAergic neuronal differentiation and migration. In the light of the strong downregulation of $A r x$ expression in $D l \times 1 / 2$ mutants, we wondered whether some of the Dlx-dependent functions might be mediated by Arx activity. For instance, because both Dlx1/2 and Arx loss of function lead to a severe reduction of GABAergic tangential migration (Anderson et al., 1997b, 2001; Kitamura et al., 2002; Colombo et al., 2007), we tested whether Dlx1/2-induced migration is relying on a sustained Arx expression. Therefore, we assessed whether Arx reexpression in a $D l x 1 / 2$ mutant background was sufficient to rescue neuronal migration activity. As an experimental system, we misexpressed either EGFP or Arx-IRES-EGFP in wild-type or $D l x 1 / 2$ mutant ventral forebrain. On the following day, we transplanted the MGE electroporated tissue in the homologous region of the contralateral side of cultured brain slices. Using this approach, GFP-expressing neurons could be clearly followed during their migration from the transplanted MGE outward in the striatum and cortex (Fig. 9A-C). As expected, $48 \mathrm{~h}$ after transplantation, GFP $+D l \times 1 / 2$ mutant cells exhibited an almost negligible migration ability from the transplanted MGE, in all cases analyzed ( 8 of 8 ) (Fig. 9D-F). On the contrary, a robust number of $D l x 1 / 2$ mutant-Arx-overexpressing cells showed a sustained migration from the transplanted MGE, reaching in some cases also the basolateral cortex (Fig. 9G-I). To quantify this rescue in migration ability, we subdivided the forebrain into four consecutive domains centered on the transplanted MGE and counted the number of GFP + cells present in each domain. Arx overexpression in $D l x 1 / 2$ mutant cells induced an approximately fivefold increase in cell migration in the first three domains (Fig. 9J). This represented an $\sim 65 \%$ rescue in first and second proximal domains, and an $\sim 32 \%$ rescue in the distal areas, compared with wild type (Fig. 9J).

Hence, Arx overexpression in $D l x 1 / 2$ mutant can efficiently rescue migration activity defects in a $D l \times 1 / 2$ mutant context, in particular in MGE proximal domains. Conversely, Arx overexpression in Dlx1/2-deficient cells failed to promote long-term 
migration in the fourth most distal domain, at least in a $48 \mathrm{~h}$ time window.

Dlx1/2/5 ectopic expression is sufficient to activate some aspects of GABAergic cell fate specification, such as GAD65/67 expression in the neural progenitors of the cerebral cortex normally committed to a glutamatergic phenotype (Stühmer et al., 2002). Therefore, Dlx genes appear instrumental in promoting initial aspects of GABAergic differentiation at least in a heterologous forebrain domain. We wondered whether this aspect of the Dlx function might be affected by Arx activity, because Dlx ectopic activity triggered Arx expression as previously described. To answer this question, E13.5 Arx-deficient brain slices were electroporated in the lateral cortex with a Dlx2IRES-GFP expression vector and maintained in culture for $30 \mathrm{~h}$ before final analysis. As in wild-type brain slices (data not shown), Dlx2 efficiently activated GAD65 protein in Arx mutant cortical progenitors as detected with a specific antibody (monoclonal GAD65; Sigma) (Fig. $10 A-C)$. Arx inactivation was achieved by replacing the Arx coding sequence with a LacZ reporter gene. This approach also allowed the detection of the activation of the Arx endogenous locus by following $\beta$-galactosidase activity (Collombat et al., 2003). Hence, electroporated Dlx 2 cortical cells were expected to coexpress GAD65 together with $\beta$-galactosidase. Indeed, we detected a virtual complete overlapping expression pattern between GFP and $\beta$-galactosidase activation (Fig. 10D-F). These findings suggest that the acquisition of GABAergic cell features promoted by Dlx activation does not rely on a functional Arx allele.

Together, these results provide evidence that Arx is necessary to promote Dlx-dependent GABAergic cell migration, but is dispensable for Dlx ability to induce GABAergic cell fate commitment.

\section{Discussion}

In this study, we report the identification and functional characterization of the Arx GABAergic enhancer and disclose the biological significance of the Dlx-Arx genetic hierarchy. Arx-specific forebrain expression is achieved by the spatial combinatorial expression promoted by at least two independent enhancers located downstream of the Arx coding region and $8 \mathrm{~kb}$ apart. The molecular mechanisms regulating Arx expression through these two domains appear completely divergent, because Dlx is not involved in controlling the activity of the cortical Arx enhancer, which presents a specific set of transcription factorbinding elements (G. Colasante and V. Broccoli, unpublished results). Hence, Arx expression is accomplished by independently regulated enhancer modules that appear separated and distributed

J
Oh

$48 \mathrm{~h}$
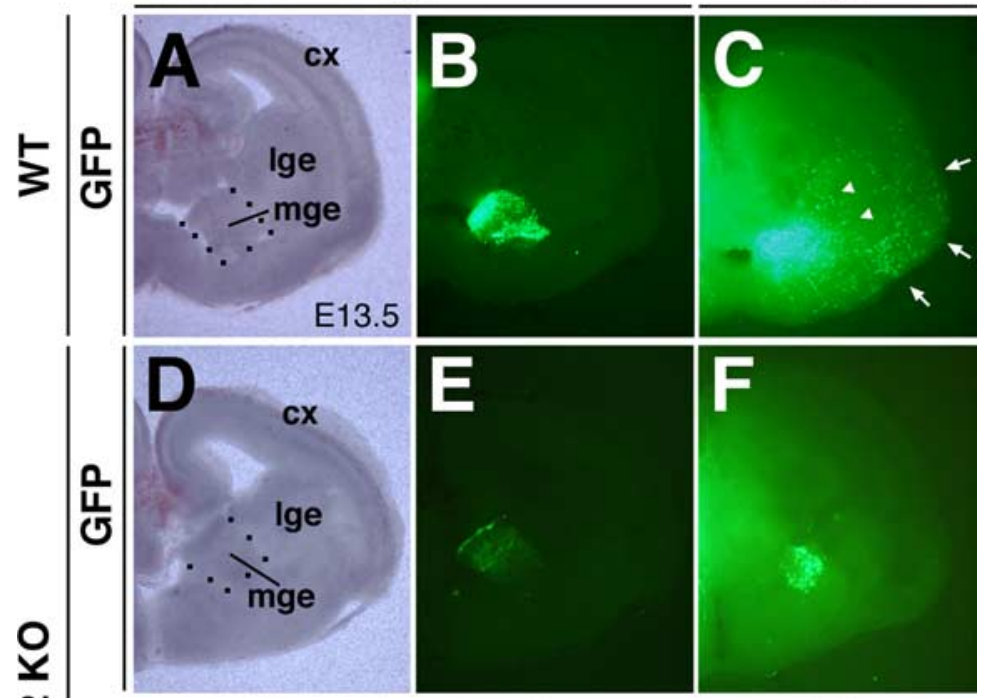

Oh

$24 \mathrm{~h}$
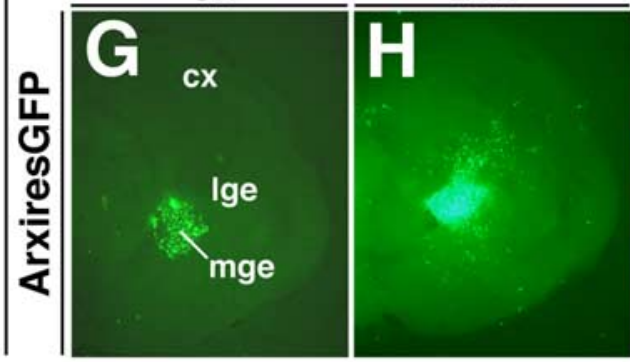

$48 \mathrm{~h}$
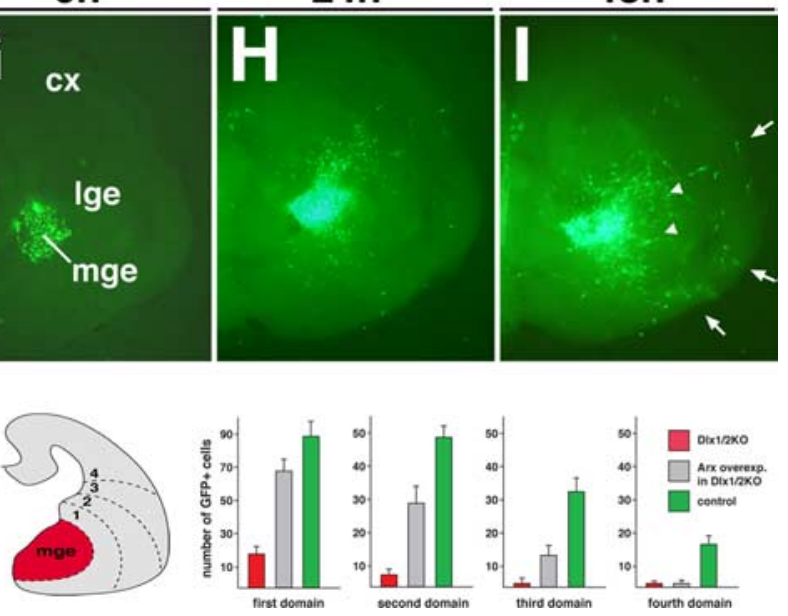

Figure 9. Arx overexpression in Dlx1/2 mutant MGE partially rescues tangential migration of interneurons. $\boldsymbol{A}-\boldsymbol{C}$, Representative example of GFP + cells that migrated toward the LGE (C, arrowheads) and the cortex (cx) (C, arrows) 48 h after transplantation of the electroporated MGE in a corresponding position of the contralateral side (area highlighted with dots in $A$ ) of wild-type (WT) E14.5 forebrain slice organotypic cultures. $\boldsymbol{D}, \boldsymbol{E}, \mathbf{G}$, Transplantation of the electroporated Dlx1/2 mutant MGE with GFP $(\boldsymbol{D}, \boldsymbol{E})$ or $\operatorname{Arx}$-IRES-GFP $(\boldsymbol{G})$ transplanted into the contralateral side of DIx1/2 mutant forebrain brain slices. $\boldsymbol{F}$, $\boldsymbol{I}$, Migration of GFP + cells after $48 \mathrm{~h}$ from the transplantation in Dlx1/2 mutant tissue. Whereas GFP cells failed to migrate outwards from the grafting $(\boldsymbol{F})$, Arx-overexpressing cells show an extensive migration ability, with cells migrated distant from the transplanted MGE tissue toward the cortex (arrows) and the lateral ganglionic eminence (arrowheads) ( $\boldsymbol{I}$ ). $\boldsymbol{J}$, Quantification of numbers of GFP + cells in the cortex of WT and Dlx1/2 mutant tissues. For counting, four consecutive domains organotypic brain slices were independently analyzed (from 1 proximal to the transplanted MGE to 4, the most distal region), with the first two domains covering the LGE domain and the last two comprising the lateral and mediolateral cortices, respectively. Nine different brain slices for each experimental setup were counted, obtained in three independent experiments. The total numbers of GFP + cells for Dlx mutant cells (red bars), Arx-overexpressing (overexp.) cells in the Dlx1/2 mutant tissue (gray bars), and control cells in WT tissue (green bars) were as follows: in domain 1, $13 \pm 4,67 \pm 11$, and $91 \pm 15$, respectively; in domain 2, 4 $\pm 3,29 \pm 10$, and $48 \pm 15$, respectively; in domain $3,2 \pm 2,12 \pm 5$, and $33 \pm 7$, respectively; in domain 4, 0,2 \pm 2 , and $18 \pm 5$, respectively. K0, Knock-out.

along the genome. It is intriguing that both Arx enhancer elements are highly conserved from fugu to human, suggesting a relevant function of Arx in neuroanatomical features of the ancestral vertebrate cerebrum. The GABAergic enhancer element is located $13 \mathrm{~kb}$ downstream to the last Arx exon and enclosed in the last intron of the PolA1 gene. This is a very peculiar site for an enhancer element, being contained in a different gene from the one it is controlling. This structural organization is conserved in different vertebrates, raising the question of how this could be achieved and positively selected during evolution. A possibility would lie in the fact that the last three introns of the PolA1 gene are extremely large (110 kb altogether), 


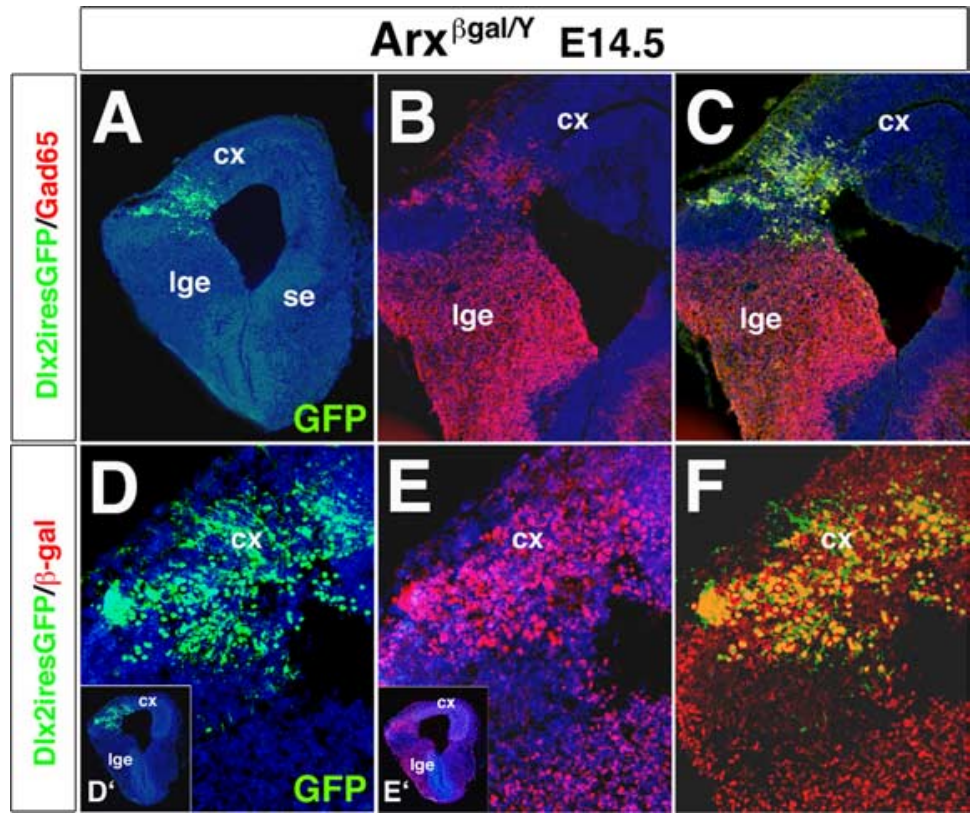

Figure 10. Dlx2 ability to ectopically induce GABAergic gene expression is retained in the absence of Arx activity. $\boldsymbol{A}-\boldsymbol{C}$, A single coronal section from an E14.5 Arx mutant mouse brain electroporated $30 \mathrm{~h}$ earlier with Dlx2iresGFP. Dlx2-targeted tissue in the lateral cerebral cortex is activating GAD65 expression. $\mathbf{D}-\boldsymbol{F}$, A single coronal section from an electroporated Arx mutant mouse brain. Dlx2 ectopic expression activates the LacZ gene activity, which is knocked into the Arx endogenous locus and acts as a sensor of the Arx endogenous enhancer activity. $\boldsymbol{C}$, Merge image of $\boldsymbol{A}$ and $\boldsymbol{B}$. $\boldsymbol{F}$, Merge image of $\boldsymbol{D}$ and $\boldsymbol{E}$. $\boldsymbol{D}, \boldsymbol{E}$, Enlargements of the brain sections shown as a whole in insets $\boldsymbol{D}^{\prime}$ and $\boldsymbol{E}^{\prime}$. cx, Cerebral cortex; se, septum.

and therefore evolutive pressure may have been applied in these sequences without affecting the PolA1 gene transcription.

Recently, highly evolutionarily conserved noncoding regions were identified in systematic studies analyzing the whole human genome (Bejerano et al., 2004; Woolfe et al., 2005; Pennacchio et al., 2006). In particular, Bejerano et al. (2004) isolated 481 nucleotide segments, coined as ultraconserved elements, which are absolutely conserved between orthologous regions of the rat and mouse genomes (100\% identity), and display a significant homology in chicken and fish. Interestingly, five of these conserved sequence modules were detected in the last introns of the POLA1 gene, and one of them (uc.467) was included into the Arx GABAergic enhancer sequence herein analyzed. Because in our functional analysis the enhancers controlling Arx expression in testis and muscles were not identified, it is conceivable that these sequences may lie on the other conserved sequences within the PolA1 gene, but located at least $20 \mathrm{~kb}$ away downstream to the Arx coding region. Ultraconserved elements in the human genome have been shown to exhibit almost no natural variation in the overall population, with a rate of nucleotide change that is $\sim 20$ times slower than the average genome (Bejerano et al., 2004). Therefore, it is conceivable that these highly conserved noncoding sequences may be a favorable substrate for the development of disease-causing mutations. The Arx GABAergic enhancer represents a good candidate as a noncoding sequence that, when mutated, may lead to Arx-specific silencing restricted to forebrain interneurons, and therefore causes the development of related neuropathological conditions (e.g., epilepsy, mental retardation, and motor deficits). Mutations in the enhancer elements of developmental genes like Shh, Ret, Pitx2, Gli3, and Pax6 have been already described to cause human congenital diseases (Emison et al., 2005; Kleinjan and van Heyningen, 2005; Gurnett et al., 2007). Thus, it would be valuable to perform a mutational screening of this Arx enhancer sequence in those highly related neurological disorders in which mutations in the Arx coding region failed to be identified.
The analysis of the expression of the GABAergic enhancer confirmed previous results on Arx endogenous expression in the great majority of cortical interneurons belonging to all the different subclasses. Notably, $\beta$-galactosidase activity was strongly detected in neurons of the adult brain. $\beta$-Galactosidase is a highly stable enzyme, which remains active for long time in the tissue, even longer, in some cases, than the endogenous protein. However, it is plausible that Arx expression is maintained in adult brain as confirmed by immunohistochemistry on mature hippocampal neurons and RNA expression profile in adult brain. Therefore, Arx may exert additional roles on mature and functional cortical interneurons. The significance of these findings remains to be assessed.

The highly conserved core of the Arx GABAergic enhancer (mUAS3) contains two recognizable binding modules for homeodomain transcription factors. Although these binding motives do not fully match the Dlx consensus binding requirement (G-A/CTAATT-A/G-G/C), we detected a very robust and specific dependence by these proteins (Dlx1/2/5). Other homeodomaincontaining proteins, such as Nkx2.1, Gsh1/2, and Isl1, are normally expressed in the ventral telencephalon and could represent putative candidates activating the Arx promoter. However, both in vitro and in vivo transient expression assays revealed that all these other proteins were unable to elicit a reliable activation of the Arx enhancer. This apparent contradiction can be explained by considering the presence of molecular partners of the Dlx proteins that can cooperate with them to promote high enhancer activation. Indeed, other sequences in the Arx enhancer flanking the putative Dlx-binding sites are extremely conserved and may act as binding elements for other transcription factors that we were unable to identify so far. This hypothesis is also supported by the finding that Arx expression is still detectable, although much weaker, in $D l x 1 / 2$ mutants, further emphasizing a role for other unidentified proteins.

Dlx proteins are key molecular players of ventral pallium development with multiple functions in GABAergic neurons, regulating various aspects of their differentiation and migration. In particular, Dlx1/2 proteins are redundant in specifying a later subset of neuronal subpallial progenitors and promoting their terminal differentiation by repressing Notch signaling (Anderson et al., 1997a; Yun et al., 2002). In addition, Dlx1/2 can promote GABAergic neuronal cell fate (Stühmer, 2002) while repressing oligodendrocyte precursor cell formation by negatively regulating Olig2 expression (Petryniak et al., 2007). During interneuron migration, Dlx1/2 proteins sustain cell motility by repressing neurite development through the inhibition of the Pak3 kinase, and lead the cellular path by controlling the expression of guidance molecules such as Neuropilin-2 (Le et al., 2007). How Dlx proteins tightly control these different processes at the molecular level is unknown. Few Dlx molecular binding proteins have been recognized so far, albeit their relevance in these processes has not been addressed yet (Sasaki et al., 2002). Therefore, it is conceivable that Dlx proteins could directly act on different molecular targets that mediate each of these different processes. Arx appears to 
be an important intermediate target of Dlx proteins, and here we show that Dlx proteins directly control its expression. However, our findings support the idea that Arx could be acting to accomplish some, but not other, Dlx-dependent genetic programs. In fact, the Dlx-Arx pathway is not required for ectopic GABAergic cell gene expression, as shown by the retained ability of Dlx2 protein to induce ectopic $\mathrm{GAD}^{+}$cells in the absence of Arx. This finding is corroborated by both the Arx failure to induce any GABAergic molecular marker when overexpressed in ectopic forebrain regions (V. Broccoli, I. Cobos, and J. Rubenstein, unpublished results) and the maintenance of GAD expression in Arx mutant brains (Colombo et al., 2007). However, these data do not entirely exclude any Arx involvement in GABAergic neuronal specification inside the ganglionic eminences, where still-undetermined molecular mechanisms are controlling GABAergic fate. In contrast, Arx has a remarkable role in promoting GABAergic interneuron migration, similarly to what was described for Dlx proteins (Anderson et al., 1997b; Kitamura et al., 2002; Colombo et al., 2007). We show here that their comparable function in this system is partially redundant, because Arx expression in $D l x 1 / 2$ mutant tissue is able to rescue interneuron migration to a certain extent (between 14 and 30\%). It has been recently described that ectopic activation of the Pak 3 kinase may account in part for the inhibition of neuronal migration in Dlx mutant brains (Cobos et al., 2007). Interestingly, we found that Pak3 is also upregulated in Arx mutants as tested by qPCRs on forebrain lysates (our unpublished results). However, the rescue obtained with Arx is quantitatively more relevant with respect to that achieved by Pak3 overexpression, indicating that Arx should also act on other still-unknown molecular players. Together, Arx may be considered a molecular switch acting downstream to Dlx proteins and contributing in the selection of the different Dlx-dependent processes.

It is worthwhile to note that both $D l x$ and Arx genes have a strong relevance in human neurodevelopmental disorders. In fact, Dlx genes were shown to be linked to epilepsy and Rett syndrome (Cobos et al., 2005b; Horike et al., 2005). Also, members of the Dlx homeobox family are found in two autismsusceptibility loci, chromosome $2 \mathrm{q}$ and $7 \mathrm{q}$ (Hamilton et al., 2005). All these neuropathological conditions are closely overlapping with those depending on Arx mutations. These findings provide evidence of a conserved functional relationship between Dlx and Arx in human brain development, which controls an overlapping transcriptional cascade with common molecular targets. Thus, this indicates that discovering other members of this molecular pathway will offer significant novel candidates possibly responsible for other related human diseases. The term interneuronopathies has been recently introduced to describe those human diseases that share all or a set of neurological symptoms, which may range from epilepsy to nonsyndromic mental retardation, that arise from the impairment of tangential GABAergic cortical interneuron migration (Kato and Dobyns, 2005). The analysis of the downstream molecular pathways controlled by Dlx and Arx transcription factors will enhance our knowledge of interneuron development and provide insights into such important neurological disorders.

\section{References}

Anderson SA, Qiu M, Bulfone A, Eisenstat DD, Meneses J, Pedersen R, Rubenstein JL (1997a) Mutations of the homeobox genes Dlx-1 and Dlx-2 disrupt the striatal subventricular zone and differentiation of late born striatal neurons. Neuron 19:27-37.

Anderson SA, Eisenstat DD, Shi L, Rubenstein JL (1997b) Interneuron migration from basal forebrain to neocortex: dependence on Dlx genes. Science 278:474-476.

Anderson SA, Marín O, Horn C, Jennings K, Rubenstein JL (2001) Distinct cortical migrations from the medial and lateral ganglionic eminences. Development 128:353-363.

Banker GA, Cowan WM (1977) Rat hippocampal neurons in dispersed cell culture. Brain Res 126:397-442.

Bejerano G, Pheasant M, Makunin I, Stephen S, Kent WJ, Mattick JS, Haussler D (2004) Ultraconserved elements in the human genome. Science 304:1321-1325.

Bienvenu T, Poirier K, Friocourt G, Bahi N, Beaumont D, Fauchereau F, Ben Jeema L, Zemni R, Vinet MC, Francis F, Couvert P, Gomot M, Moraine C, van Bokhoven H, Kalscheuer V, Frints S, Gecz J, Ohzaki K, Chaabouni H, Fryns JP, et al. (2002) ARX, a novel Prd-class-homeobox gene highly expressed in the telencephalon, is mutated in X-linked mental retardation. Hum Mol Genet 11:981-991.

Bonanomi D, Menegon A, Miccio A, Ferrari G, Corradi A, Kao HT, Benfenati F, Valtorta F (2005) Phosphorylation of synapsin I by cAMP-dependent protein kinase controls synaptic vesicle dynamics in developing neurons. J Neurosci 25:7299-7308.

Bonneau D, Toutain A, Laquerrière A, Marret S, Saugier-Veber P, Barthez MA, Radi S, Biran-Mucignat V, Rodriguez D, Gélot A (2002) X-linked lissencephaly with absent corpus callosum and ambiguous genitalia (XLAG): clinical, magnetic resonance imaging, and neuropathological findings. Ann Neurol 51:340-349.

Bulfone A, Wang F, Hevner R, Anderson S, Cutforth T, Chen S, Meneses J, Pedersen R, Axel R, Rubenstein JL (1998) An olfactory sensory map develops in the absence of normal projection neurons or GABAergic interneurons. Neuron 21:1273-1282.

Campbell G, Weaver T, Tomlinson A (1993) Axis specification in the developing Drosophila appendage: the role of wingless, decapentaplegic, and the homeobox gene aristaless. Cell 74:1113-1123.

Cobos I, Broccoli V, Rubenstein JL (2005a) The vertebrate ortholog of Aristaless is regulated by Dlx genes in the developing forebrain. J Comp Neurol 483:292-303.

Cobos I, Calcagnotto ME, Vilaythong AJ, Thwin MT, Noebels JL, Baraban SC, Rubenstein JL (2005b) Mice lacking Dlx1 show subtype-specific loss of interneurons, reduced inhibition and epilepsy. Nat Neurosci 8:1059-1068.

Cobos I, Borello U, Rubenstein JL (2007) Dlx transcription factors promote migration through repression of axon and dendrite growth. Neuron 54:873-888.

Collombat P, Mansouri A, Hecksher-Sorensen J, Serup P, Krull J, Gradwohl G, Gruss P (2003) Opposing actions of Arx and Pax4 in endocrine pancreas development. Genes Dev 17:2591-2603.

Colombo E, Galli R, Cossu G, Gécz J, Broccoli V (2004) Mouse orthologue of ARX, a gene mutated in several X-linked forms of mental retardation and epilepsy, is a marker of adult neural stem cells and forebrain GABAergic neurons. Dev Dyn 231:631-639.

Colombo E, Collombat P, Colasante G, Bianchi M, Long J, Mansouri A, Rubenstein JL, Broccoli V (2007) Inactivation of Arx, the murine ortholog of the X-linked lissencephaly with ambiguous genitalia gene, leads to severe disorganization of the ventral telencephalon with impaired neuronal migration and differentiation. J Neurosci 27:4786-4798.

Corbin JG, Nery S, Fishell G (2001) Telencephalic cells take a tangent: nonradial migration in the mammalian forebrain. Nat Neurosci 4:1177-1182.

Emison ES, McCallion AS, Kashuk CS, Bush RT, Grice E, Lin S, Portnoy ME, Cutler DJ, Green ED, Chakravarti A (2005) A common sex-dependent mutation in a RET enhancer underlies Hirschsprung disease risk. Nature 434:857-863.

Ferrai C, Munari D, Luraghi P, Pecciarini L, Cangi MG, Doglioni C, Blasi F, Crippa MP (2007) A transcription-dependent micrococcal nucleaseresistant fragment of the urokinase-type plasminogen activator promoter interacts with the enhancer. J Biol Chem 282:12537-12546.

Fode C, Ma Q, Casarosa S, Ang SL, Anderson DJ, Guillemot F (2000) A role for neural determination genes in specifying the dorsoventral identity of telencephalic neurons. Genes Dev 14:67-80.

Gécz J, Cloosterman D, Partington M (2006) ARX: a gene for all seasons. Curr Opin Genet Dev 16:308-316.

Ghanem N, Jarinova O, Amores A, Long Q, Hatch G, Park BK, Rubenstein JL, Ekker M (2003) Regulatory roles of conserved intergenic domains in vertebrate Dlx bigene clusters. Genome Res 13:533-543.

Ghanem N, Yu M, Long J, Hatch G, Rubenstein JL, Ekker M (2007) Distinct cis-regulatory elements from the Dlx1/Dlx2 locus mark different progen- 
itor cell populations in the ganglionic eminences and different subtypes of adult cortical interneurons. J Neurosci 27:5012-5022.

Guillemot F (2005) Cellular and molecular control of neurogenesis in the mammalian telencephalon. Curr Opin Cell Biol 17:639-647.

Guillemot F (2007) Cell fate specification in the mammalian telencephalon. Prog Neurobiol 83:37-52.

Guimera J, Weisenhorn DV, Wurst W (2006) Megane/Heslike is required for normal GABAergic differentiation in the mouse superior colliculus. Development 133:3847-3857.

Gurnett CA, Bowcock AM, Dietz FR, Morcuende JA, Murray JC, Dobbs MB (2007) Two novel point mutations in the long-range SHH enhancer in three families with triphalangeal thumb and preaxial polydactyly. Am J Med Genet A 143:27-32.

Hamilton SP, Woo JM, Carlson EJ, Ghanem N, Ekker M, Rubenstein JL (2005) Analysis of four DLX homeobox genes in autistic probands. BMC Genet 6:52.

Horike S, Cai S, Miyano M, Cheng JF, Kohwi-Shigematsu T (2005) Loss of silent-chromatin looping and impaired imprinting of DLX5 in Rett syndrome. Nat Genet 37:31-40.

Kato M (2006) A new paradigm for West syndrome based on molecular and cell biology. Epilepsy Res 70:S87-S95.

Kato M, Dobyns WB (2005) X-linked lissencephaly with abnormal genitalia as a tangential migration disorder causing intractable epilepsy: proposal for a new term, "interneuronopathy." J Child Neurol 20:392-397.

Kato M, Das S, Petras K, Kitamura K, Morohashi K, Abuelo DN, Barr M, Bonneau D, Brady AF, Carpenter NJ, Cipero KL, Frisone F, Fukuda T, Guerrini R, Iida E, Itoh M, Lewanda AF, Nanba Y, Oka A, Proud VK, et al. (2004) Mutations of ARX are associated with striking pleiotropy and consistent genotype-phenotype correlation. Hum Mutat 23:147-159.

Kitamura K, Yanazawa M, Sugiyama N, Miura H, Iizuka-Kogo A, Kusaka M, Omichi K, Suzuki R, Kato-Fukui Y, Kamiirisa K, Matsuo M, Kamijo S, Kasahara M, Yoshioka H, Ogata T, Fukuda T, Kondo I, Kato M, Dobyns WB, Yokoyama M, et al. (2002) Mutation of ARX causes abnormal development of forebrain and testes in mice and X-linked lissencephaly with abnormal genitalia in humans. Nat Genet 32:359-369.

Kleinjan DA, van Heyningen V (2005) Long-range control of gene expression: emerging mechanisms and disruption in disease. Am J Hum Genet $76: 8-32$.

Kuwajima T, Nishimura I, Yoshikawa K (2006) Necdin promotes GABAergic neuron differentiation in cooperation with Dlx homeodomain proteins. J Neurosci 26:5383-5392.

Le TN, Du G, Fonseca M, Zhou QP, Wigle JT, Eisenstat DD (2007) Dlx homeobox genes promote cortical interneuron migration from the basal forebrain by direct repression of the semaphorin receptor neuropilin-2. J Biol Chem 282:19071-19081.

Long JE, Garel S, Alvarez-Dolado M, Yoshikawa K, Osumi N, Alvarez-Buylla A, Rubenstein JL (2007) Dlx-dependent and -independent regulation of olfactory bulb interneuron differentiation. J Neurosci 27:3230-3243.

Marín O, Rubenstein JL (2001) A long, remarkable journey: tangential migration in the telencephalon. Nat Rev Neurosci 2:780-790.

Meijlink F, Beverdam A, Brouwer A, Oosterveen TC, Berge DT (1999) Vertebrate aristaless-related genes. Int J Dev Biol 43:651-663.

Métin C, Baudoin JP, Rakić S, Parnavelas JG (2006) Cell and molecular mechanisms involved in the migration of cortical interneurons. Eur J Neurosci 23:894-900.

Miura H, Yanazawa M, Kato K, Kitamura K (1997) Expression of a novel aristaless related homeobox gene 'Arx' in the vertebrate telencephalon, diencephalon and floor plate. Mech Dev 65:99-109.

Miyoshi G, Bessho Y, Yamada S, Kageyama R (2004) Identification of a novel basic helix-loop-helix gene, Heslike, and its role in GABAergic neurogenesis. J Neurosci 24:3672-3682.
Nakatani T, Minaki Y, Kumai M, Ono Y (2007) Helt determines GABAergic over glutamatergic neuronal fate by repressing Ngn genes in the developing mesencephalon. Development 134:2783-2793.

Nawara M, Szczaluba K, Poirier K, Chrzanowska K, Pilch J, Bal J, Chelly J, Mazurczak T (2006) The ARX mutations: a frequent cause of X-linked mental retardation. Am J Med Genet A 140:727-732.

Panganiban G, Rubenstein JL (2002) Developmental functions of the Distal-less/Dlx homeobox genes. Development 129:4371-4386.

Pennacchio LA, Ahituv N, Moses AM, Prabhakar S, Nobrega MA, Shoukry M, Minovitsky S, Dubchak I, Holt A, Lewis KD, Plajzer-Frick I, Akiyama J, De Val S, Afzal V, Black BL, Couronne O, Eisen MB, Visel A, Rubin EM (2006) In vivo enhancer analysis of human conserved non-coding sequences. Nature 444:499-502.

Petryniak MA, Potter GB, Rowitch DH, Rubenstein JL (2007) Dlx1 and Dlx2 control neuronal versus oligodendroglial cell fate acquisition in the developing forebrain. Neuron 55:417-433.

Pleasure SJ, Anderson S, Hevner R, Bagri A, Marin O, Lowenstein DH, Rubenstein JL (2000) Cell migration from the ganglionic eminences is required for the development of hippocampal GABAergic interneurons. Neuron 28:727-740.

Poirier K, Van Esch H, Friocourt G, Saillour Y, Bahi N, Backer S, Souil E, Castelnau-Ptakhine L, Beldjord C, Francis F, Bienvenu T, Chelly J (2004) Neuroanatomical distribution of ARX in brain and its localisation in GABAergic neurons. Brain Res Mol Brain Res 122:35-46.

Poitras L, Ghanem N, Hatch G, Ekker M (2007) The proneural determinant MASH1 regulates forebrain Dlx1/2 expression through the I12b intergenic enhancer. Development 134:1755-1765.

Qiu M, Bulfone A, Ghattas I, Meneses JJ, Christensen L, Sharpe PT, Presley R, Pedersen RA, Rubenstein JL (1997) Role of the Dlx homeobox genes in proximodistal patterning of the branchial arches: mutations of Dlx-1, Dlx-2, and Dlx-1 and - 2 alter morphogenesis of proximal skeletal and soft tissue structures derived from the first and second arches. Dev Biol 185:165-184.

Sasaki A, Masuda Y, Iwai K, Ikeda K, Watanabe K (2002) A RING finger protein Prajal regulates Dlx5-dependent transcription through its ubiquitin ligase activity for the Dlx/Msx-interacting MAGE/Necdin family protein, Dlxin-1. J Biol Chem 277:22541-22546.

Strømme P, Mangelsdorf ME, Shaw MA, Lower KM, Lewis SM, Bruyere H, Lütcherath V, Gedeon AK, Wallace RH, Scheffer IE, Turner G, Partington M, Frints SG, Fryns JP, Sutherland GR, Mulley JC, Gécz J (2002) Mutations in the human ortholog of Aristaless cause X-linked mental retardation and epilepsy. Nat Genet 30:441-445.

Stühmer T, Anderson SA, Ekker M, Rubenstein JL (2002) Ectopic expression of the Dlx genes induces glutamic acid decarboxylase and Dlx expression. Development 129:245-252.

Wonders CP, Anderson SA (2006) The origin and specification of cortical interneurons. Nat Rev Neurosci 7:687-696.

Woolfe A, Goodson M, Goode DK, Snell P, McEwen GK, Vavouri T, Smith SF, North P, Callaway H, Kelly K, Walter K, Abnizova I, Gilks W, Edwards YJ, Cooke JE, Elgar G (2005) Highly conserved non-coding sequences are associated with vertebrate development. PLoS Biol 3:e7.

Yoshihara S, Omichi K, Yanazawa M, Kitamura K, Yoshihara Y (2005) Arx homeobox gene is essential for development of mouse olfactory system. Development 132:751-762.

Yun K, Fischman S, Johnson J, Hrabe de Angelis M, Weinmaster G, Rubenstein JL (2002) Modulation of the notch signaling by Mash1 and Dlx1/2 regulates sequential specification and differentiation of progenitor cell types in the subcortical telencephalon. Development 129:5029-5040.

Zappavigna V, Sartori D, Mavilio F (1994) Specificity of HOX protein function depends on DNA-protein and protein-protein interactions, both mediated by the homeo domain. Genes Dev 8:732-744. 